\title{
Aerodynamic loads and bridge responses under train passage: case study of an overpass steel box-girder cable-stayed bridge
}

\author{
Ziqi Liu, Xun Zhang ${ }^{*}$ (i), Tao Chen, Yuyi Liu and Bin Lu
}

\author{
${ }^{*}$ Correspondence: \\ zhxunxun@swjtu.edu.cn \\ Department of Bridge \\ Engineering, Southwest \\ Jiaotong University, \\ Chengdu 610031, China
}

\begin{abstract}
Increased train speeds have led to significant train-induced wind problems. This paper describes a numerical study of the aerodynamic loads produced when a train passes under a bridge and the bridge dynamic response based on a steel box-girder cablestayed bridge. The results indicate that the wind pressure on the bottom plate and the maximum lift on the beam sections increase as the train speed increases or as the clearance under the bridge decreases. Changes in the intersection angle are found to have a greater impact on the 1/4-span and 3/4-span regions. The effects of the various influencing factors are basically the same in the construction and operation stages. As the train speed increases or the clearance under the bridge decreases, the bridge responses exhibit an upward trend. As the intersection angle decreases, the vibration displacement tends to increase, but the effects on the vibration acceleration and maximum counter-force of the temporary pier are not consistent. Compared with the construction stage, the dynamic responses of the main girder are smaller in the operation stage due to the larger overall rigidity and the support constraints. In the parameter ranges investigated in this study, the absolute values of maximum vertical bridge vibration displacement and acceleration decrease from 4 to $16 \mathrm{~mm}$ and from 85 to $400 \mathrm{~mm} / \mathrm{s}^{2}$, respectively, in the construction stage to $1-5 \mathrm{~mm}$ and $42-174 \mathrm{~mm} / \mathrm{s}^{2}$ in the operation stage. Moreover, the counter-force falling on the temporary pier after the main girder turns does not exceed the 2000-kN positive force or 300-kN negative force limits. In the operation stage, the bridge vibration responses will not affect the comfort of pedestrians.
\end{abstract}

Keywords: Aerodynamic load, High-speed train, Bridge, Steel box-girder

\section{Introduction}

In recent years, there have been rapid developments in high-speed trains. With increases in train speeds, the interaction between the trains and the surrounding air has become more significant. Thus, aerodynamics are now a crucial problem for high-speed trains (Schetz 2001).

Current research on the aerodynamic forces created by trains mainly focuses on three methods: scale model testing (e.g., wind tunnel tests, dynamic model tests), real train tests, and numerical simulations. Baker and Brockie (1991) conducted wind tunnel author(s) and the source, provide a link to the Creative Commons licence, and indicate if changes were made. The images or other third party material in this article are included in the article's Creative Commons licence, unless indicated otherwise in a credit line to the material. If material is not included in the article's Creative Commons licence and your intended use is not permitted by statutory regulation or exceeds the permitted use, you will need to obtain permission directly from the copyright holder. To view a copy of this licence, visit http:// creativecommons.org/licenses/by/4.0/. 
model experiments on aerodynamic resistance using 1:20, 1:40, and 1:76 scale train models, and compared the model-scale results with full-scale vehicles. It was found that smaller model scales produced a greater error in the measurement results. Willemsen (1997) found better agreement when the data extrapolated from high-Reynolds-number wind tunnel tests were compared with full-scale results. Hemida and Krajnović (2009) numerically simulated the flow field around a train using the large eddy simulation (LES) framework, and studied the influence of different wind deflection angles and head shapes on the flow structure and train aerodynamics. An experimental study using a train-wind dynamic model was conducted by Bell et al. (2015), who reported that the peak values of the train wind curves in the near-weak region of two- and three-car train models are different, showing distinct wake structure features. Soper et al. (2017) carried out full-scale measurements of the air flow characteristics and track characteristics under a high-speed railway in Britain, and analyzed the dynamic relationship between the undertrain airflow, track, and ballast. Niu et al. (2018) adopted the delayed detached eddy simulation with improved wall-modeling capability to simulate the unsteady aerodynamic performance of a tapered train head with lengths of $8 \mathrm{~m}$ and $12 \mathrm{~m}$, and verified the correctness of the numerical simulations through wind tunnel tests. Jiang et al. (2021) studied the aerodynamic performance of a train model through computational fluid dynamics (CFD) and detached eddy simulations, and verified the numerical method by wind tunnel tests.

The train-induced pressure will increase rapidly with an increase in the train running speed. The airflow surrounding adjacent structures can be as severe as that in a wind storm. Therefore, it is necessary to predict the aerodynamic load on structures close to the track to aid in their design. Gerhardt and Krüger (1998) investigated the wind- and train-induced air movements in train stations and discussed the means of controlling them to prevent excessive air infiltration into the stations. Baker et al. (2014) studied the transient aerodynamic pressures and forces on trackside and overhead structures due to passing trains. Formulas for the aerodynamic loading on trackside structures, which may be useful in future revision of standards, were then derived from the experimental data. Yang et al. (2015) used the FLUENT software and sliding grid technology to investigate how the beam width and beam depth influence the wind pressure on the beam surface when high-speed trains pass under a bridge. Lü et al. (2018) conducted an experimental study on the aerodynamic load characteristics of noise reduction barriers in terms of train speed, distance between the train and sound barrier, and train type. Rocchi et al. (2018) carried out a full-scale experimental test on Italian high-speed trains that obtained experimental results in different environments, and comprehensively compared the fluctuating wind pressure acting on the sound barrier for three different types of high-speed trains operating in the open air. Liu et al. (2019) measured the pressure characteristics of a tunnel when high-speed trains pass through, and studied the effects of train speed, train length, and the intersection of two trains on the peak tunnel wall pressure. Xiong et al. (2020) conducted a field test on the pressure changes caused by a CRH380A train passing the bridge sound barrier. They obtained the fluctuating pressure time history curve and wind pressure peak, and further analyzed the influence of train speed, operating track, measuring point position, marshalling lengths, and ambient wind speed on the peak wind pressure. Zheng et al. (2020) studied the aerodynamic 
pressure waves produced by high-speed trains passing through a semi-closed sound barrier by establishing CFD and finite element (FE) models.

To date, the aerodynamic characteristics and generation mechanism of train-induced pressure have been intensively studied. However, the effects of the train running speed under a bridge and the relative positions of the bridge and the train on the aerodynamic characteristics and bridge dynamic response require further research. In this study, the aerodynamic characteristics and dynamic response of a steel box-girder cable-stayed bridge are studied in the case of a high-speed train passing underneath. The intersection angle between the bridge and the existing railway is about $66^{\circ}$, and there are 10 railway lines at the intersection. The bridge span layout is $(40+188+55) \mathrm{m}$, as shown in Fig. 1. The reliability of the numerical simulations is initially verified using existing experimental data. The numerical and FE analysis models of train-induced wind are then established for the case of a high-speed train passes underneath the bridge, and the aerodynamic characteristics and variation pattern are investigated in terms of the train speed, clearance under the bridge, and train-bridge intersection angle. Finally, the dynamic responses of the bridge are studied during the construction and operation stages.

\section{Numerical simulation strategy}

Turbulence can be simulated based on CFD technology by either direct or indirect numerical simulations. The direct numerical simulation (DNS) method is relatively accurate due to its direct solution to the turbulence control equation (Piller et al. 2002; Wissink 2003), but it is seldom used in engineering because of its high computational requirements. The indirect numerical simulation method approximates or simplifies the turbulence to a certain extent, without directly solving the pulsation characteristics. Indirect approaches include LES, Reynolds-averaged Navier-Stokes (RANS) equations, and statistical averaging. The RANS method, which is widely used in practical engineering, averages the transient control equations over time and expresses variables in terms of time-averaged and fluctuation components, which has high accuracy and avoids a large number of calculations (Rollet-Miet et al. 1999). The two-equation RANS model is the most important turbulence model because it can predict the given turbulence characteristics without knowing the turbulence structure in advance. Two-equation models include the $k-\omega$ turbulence model (Bouras et al. 2018; Devolder et al. 2018), standard $k-\varepsilon$ turbulence model, and renormalization group $k-\varepsilon$ turbulence model (Liu et al. 2017), among others (Baker et al. 2014). The standard $k-\varepsilon$ turbulence model (Launder and Spalding 1972) has become widely used because of its efficiency, accuracy, and adaptability.

\subsection{Basic theory}

The standard $k-\varepsilon$ turbulence model is based on the concept of eddy viscosity. In the turbulence model, partial differential equations for $k$ and $\varepsilon$ are solved, where $k$ is the turbulent kinetic energy and $\varepsilon$ is the dissipation of $k$ (Olsen 2000). The motion equations corresponding to $k$ and $\varepsilon$ can be expressed as: 


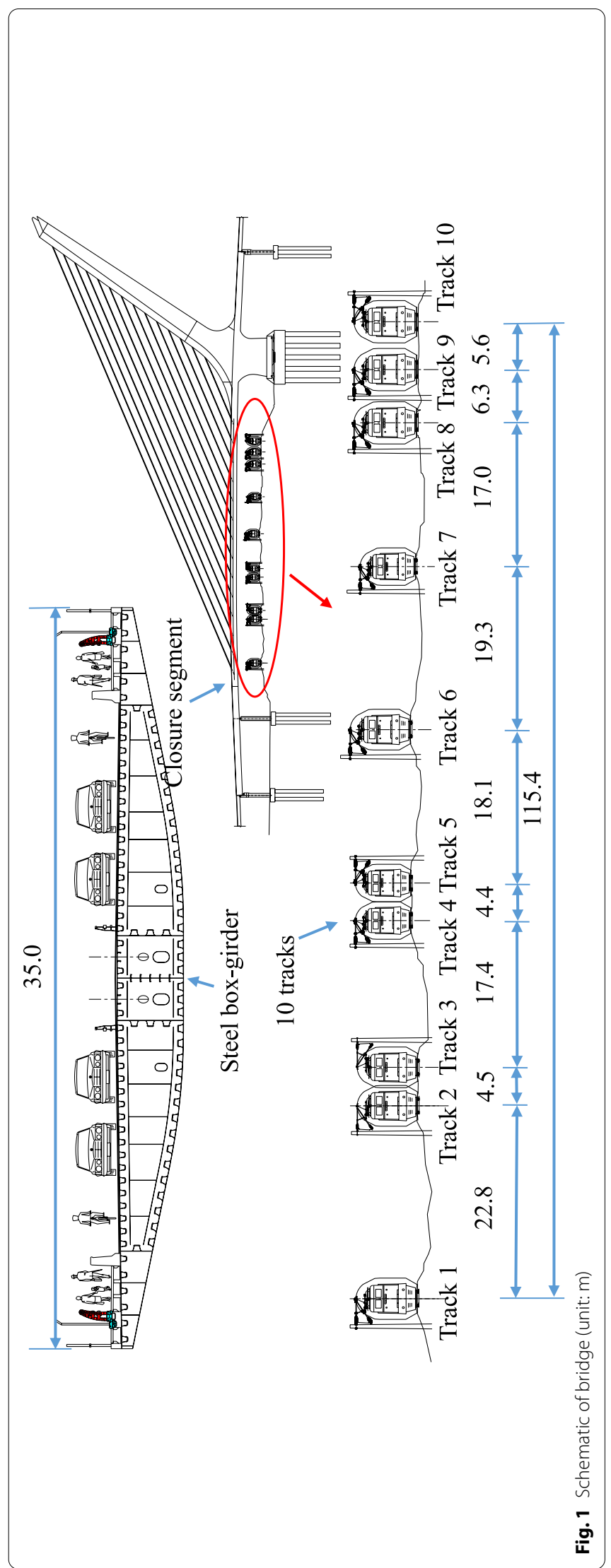




$$
\begin{aligned}
& \frac{\partial(\rho k)}{\partial t}+\frac{\partial\left(\rho k u_{i}\right)}{\partial x_{i}}=\frac{\partial}{\partial x_{i}}\left[\left(\mu+\frac{\mu_{t}}{\sigma_{k}}\right) \frac{\partial k}{\partial x_{i}}\right]+G_{k}+G_{b}-\rho \varepsilon \\
& \frac{\partial(\rho \varepsilon)}{\partial t}+\frac{\partial\left(\rho \varepsilon u_{i}\right)}{\partial x_{i}}=\frac{\partial}{\partial x_{i}}\left[\left(\mu+\frac{\mu_{t}}{\sigma_{\varepsilon}}\right) \frac{\partial \varepsilon}{\partial x_{i}}\right]-C_{2 \varepsilon} \rho \frac{\varepsilon^{2}}{k}+C_{1 \varepsilon} \frac{\varepsilon}{k}\left(G_{k}+G_{3 \varepsilon} G_{b}\right)
\end{aligned}
$$

where $G_{b}$ and $G_{3 \varepsilon}$ are related to buoyancy (which can be ignored in this study), $\rho$ is the fluid density (taken to be $1.225 \mathrm{~kg} / \mathrm{m}^{3}$ ), $u_{i}$ is the velocity vector, $t$ is the time variable, $x_{i}$ is the space tensor, $\mu$ is the molecular viscosity, $\mu_{t}$ is the viscosity coefficient, and $G_{k}$ is the increased turbulent kinetic energy. $\sigma_{k}$ and $\sigma_{\varepsilon}$ are the turbulent Prandtl numbers for $\mathrm{k}$ and $\varepsilon$, and $C_{1 \varepsilon}$ and $C_{2 \varepsilon}$ are model coefficients: $C_{1 \varepsilon}=1.44, C_{2 \varepsilon}=1.92, \sigma_{k}=1.0, \sigma_{\varepsilon}=1.3$ (Zheng et al. 2020).

The formulas for calculating $\mu_{t}$ and $G_{k}$ are (Markatos 1986):

$$
\begin{aligned}
& \mu_{t}=\rho C_{\mu} \frac{k^{2}}{\varepsilon} \\
& G_{k}=\mu_{t} S^{2}
\end{aligned}
$$

where $S$ is the modulus of the average strain rate tensor, $S=\sqrt{2 S_{i j} S_{i j}}$. The strain rate tensor $S_{i j}=\frac{1}{2}\left(\frac{\partial U_{i}}{\partial x_{j}}-\frac{\partial U_{j}}{\partial x_{i}}\right)$, where $U_{i}$ and $U_{j}$ are the double-averaged velocity components in the $x_{i}$ and $x_{j}$ directions, respectively. The model constant $C_{\mu}=0.09$.

\subsection{Model validation}

To verify the reliability of the FLUENT numerical simulation results, an aerodynamic model was established to simulate a footbridge previously studied by Yang et al. (2015), and the measured data were compared with the simulation results. The footbridge is located at the centerline of the railway station and has an overall length, clear width, and clear construction height of $82 \mathrm{~m}, 15 \mathrm{~m}$, and $2.2 \mathrm{~m}$, respectively. The structural form is a steel structure with a reinforced concrete composite bridge deck. A photograph of the bridge is shown in Fig. 2a.

The train type considered in this study is the CRH380, which has a streamlined appearance. On the premise of ensuring the calculation accuracy, the bogie, wheel rail, and pantograph structures were ignored, and only the aerodynamic shape of the train was retained and smoothed (Zheng et al. 2020; Yang et al. 2015). Numerical simulations of the train-induced wind pressure were carried out on a CRH380 train with eight carriages, as shown in Fig. 3.

Considering the influence range of the train-induced wind pressure, only the main span beam above the train was considered in establishing the aerodynamic model. To avoid the influence of the flow field boundary on the calculation results, the final calculation domain size was taken as $720.0 \times 168.0 \times 78.6 \mathrm{~m}$. The initial position of the train was $108 \mathrm{~m}$ away from the beam flange. The top and surroundings of the fluid domain adopted periodic boundary conditions. The ground, train body, and bridge surface adopted non-slip wall boundary conditions. Data exchange between the 

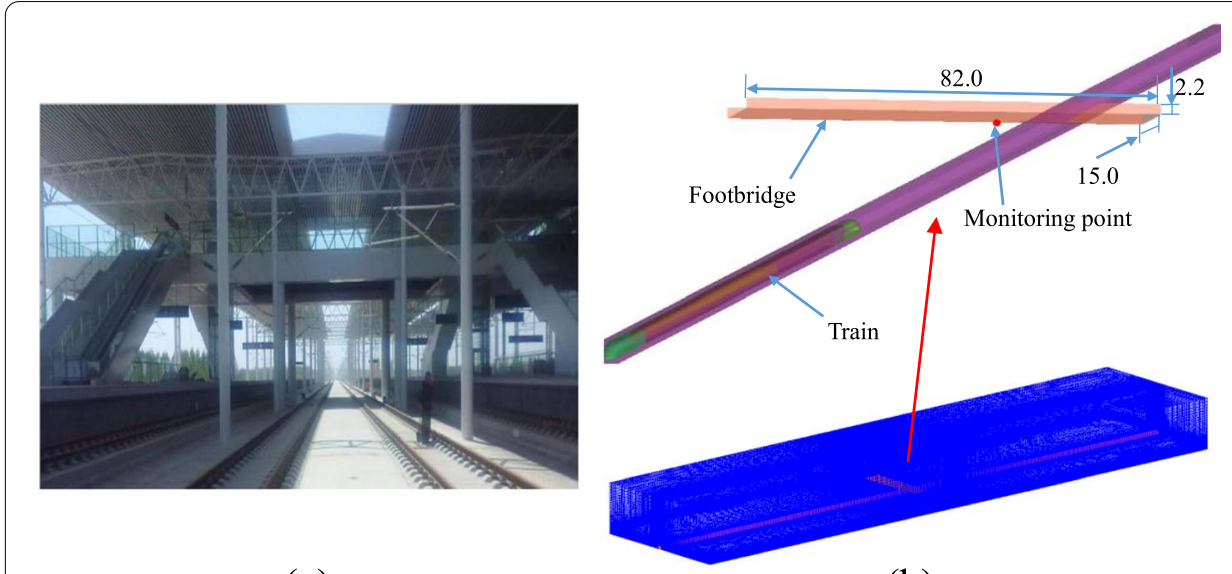

(a)

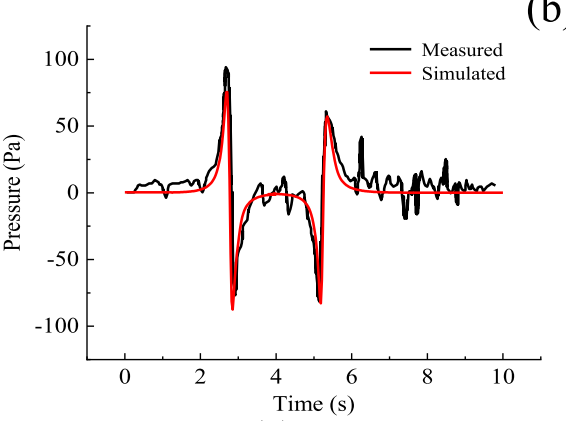

(b)

(c)

Fig. 2 Model verification of an overpass bridge: a photograph of overpass bridge (Yang et al. 2015); b model of high-speed train crossing under overpass bridge (unit: $\mathrm{m}$ ); c comparison of simulated and measured wind pressure

dynamic grid and the static grid was realized through the interface. The final volume grid consisted of approximately 3.63 million elements, as shown in Fig. 2b.

The measuring points on the bridge surface were located at the bottom of the windward surface, vertically perpendicular to the train operation direction, with a vertical distance of $4.5 \mathrm{~m}$ from the top of the train. A comparison of the time history between the simulated and measured wind pressures at the measuring points is shown in Fig. 2c. The simulated and measured train wind time histories are basically consistent, but the simulation results are relatively smooth. This is because the RANS method only gives the average pressure, rather than the fluctuating pressure. Nevertheless, it is acceptable since the measured results obtained by Yang et al. (2015) also showed that the low-frequency component dominated while the high-frequency pulsation component was small. The absolute differences between the extrema of the simulated "head wave" and "tail wave" and the measured values are less than $10 \mathrm{~Pa}$ and $3 \mathrm{~Pa}$, respectively, and the simulation error is about $10 \%$, which is within an acceptable range.

\section{Aerodynamic modeling}

This section introduces the train model and modeling parameters as described in Section 2. The computational domain size is $720.0 \times 208.0 \times 47.6 \mathrm{~m}$, as shown in Fig. 4 . To guarantee the numerical accuracy and efficiency, the layering mesh technique is 


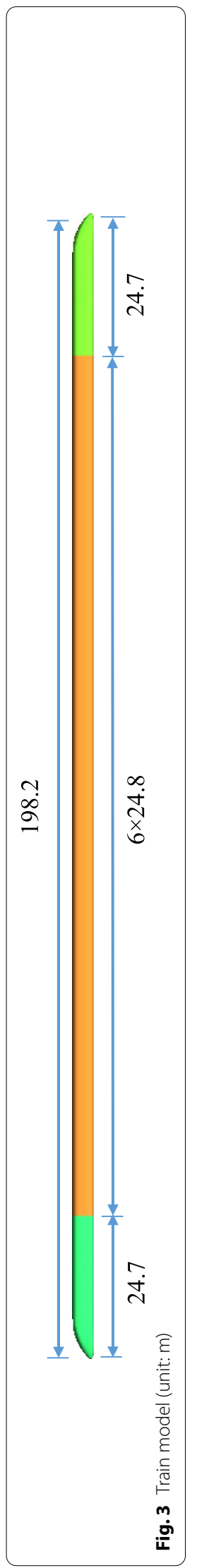




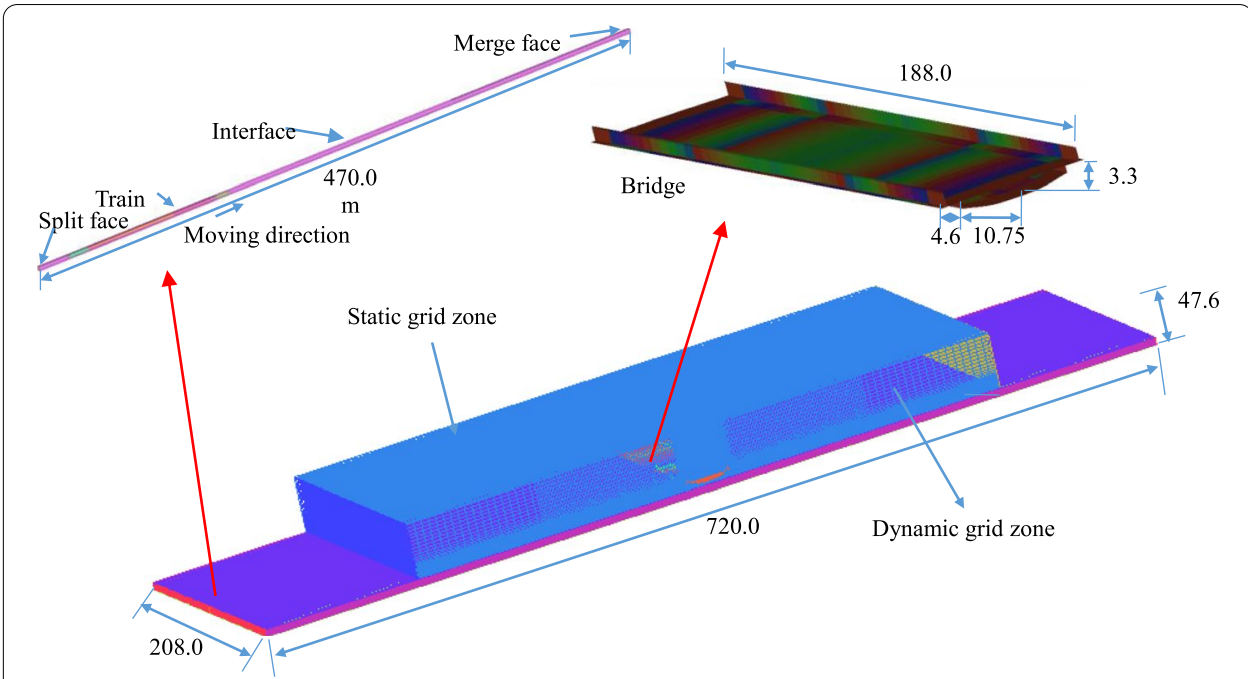

Fig. 4 Flow field model (unit: $m$ )

applied. The simulation domain is divided into two parts: a stationary domain including the overpass bridge and the surrounding flow field, and a moving domain including the train. The contact face between the moving and stationary domains is defined as an interface to exchange data. When the train moves forward, its front part compresses grids and the rear part stretches the grids, resulting in grid reconstruction in the dynamic domain. The grid height is $0.5 \mathrm{~m}$ in dynamic domain, which decides the time of grids creating and destroying. The grid destroying coefficient is 0.2 and the grid splitting coefficient is 0.4 . The train is initially $108 \mathrm{~m}$ away from the girder flange.

The computational grid is generated hierarchically. Since the overhead bridge surface is the area of concern, a finer structured grid is used to define these areas, while for the rest a coarser grid is adopted. For the calculation mesh of the moving domain, faces covering the train body are created and meshed first. The volume around the train is then meshed. Note that not only hexahedral, but also tetrahedral elements are applied for the air volume around the train because of the complex geometry of the train. The final number of elements is approximately 4.80 million. Grid independence test results show that the average pressure on the monitoring region obtained by further refining the grid has limited changes $(<5 \%)$. Thus the current model can ensure the validity of the calculated results.

It is worth mentioning that this paper does not aim at accurately modeling the flow features around the bridge girder. And, as a matter of fact, for the studied bridge girder with such a complex configuration, one can hardly obtain a mesh-independent solution regarding the flow features since it is very sensitive to the mesh size (Bruno et al. 2012). Nevertheless, from the engineering practical perspective, the modeling methodology itself is generally accepted. The innovation of this study is believed to provide insights regarding the anticipated aerodynamic loads and dynamic responses of the overpass bridge. The results will be also used in deciding particulars during the bridge design stage. 
Figure 5 shows a schematic diagram of the main span beam section and the block division of L1. To obtain a more detailed response condition of the beam, the main span is divided into 19 beam sections at 5-m intervals along the longitudinal bridge direction on the left and right, which are denoted as L1-L19 and R1-R19, respectively. The train is located in the middle of the main span, as shown in Fig. 5a. "Windward side" refers to the surface on the same side as the initial position of the train, with the beam centerline as the boundary, while "Leeward side" refers to the surface on the opposite side; "a-di-1" corresponds to the first bottom plate on the windward side (see Fig. 5b).

The aerodynamic model illustrated in Fig. 4 is used to analyze the wind pressure characteristics of the beam surface when a high-speed train passes under the bridge. The train speed is $350 \mathrm{~km} / \mathrm{h}$, the clearance under the bridge is $7.25 \mathrm{~m}$, and the intersection angle between the train and the bridge is $90^{\circ}$. Figure 6 shows wind pressure nephograms at the beam surface when the train is at different positions.

As shown in Fig. 6, when the train passes under the bridge, the surrounding flow field presents a typical three-dimensional distribution, with positive and negative pressure peaks spreading from the head and tail of the train, forming an ellipsoidal wind pressure distribution on the beam surface. For the different positions illustrated in the figure, the wind pressure on the beam surface alternates in the form "positive-negative-negative-positive". Before the nose of the head carriage reaches the beam body, the beam is basically only subjected to positive pressure. After the head of the train has entered the beam body, the beam body is subjected to both positive and negative pressure. After the nose of the head carriage has moved out of the beam body, the beam body is basically only subjected to negative pressure. The aerodynamic action of the train's tail exhibits the opposite pattern. The absolute values of the extreme positive and negative wind pressures are roughly equal when the nose of the head carriage and the tail of the train reach the centerline of the beam. The extreme values of wind pressure when the head and tail of the train nose reach the centerline of the beam are $302.5 \mathrm{~Pa}$ and $-294.7 \mathrm{~Pa}$, respectively. It is clear that the predicted wind pressure magnitudes and variation characteristics in this study are judged comparable to related field measurements (Yang et al. 2015) and CFD simulations (Yan et al. 2014).

\section{Factors influencing the aerodynamic loads}

The aerodynamic model is now used to examine the influence of train speed, bridge clearance, and the intersection between train and bridge on the wind pressure on the girder surface and the lift force on the girder section.

\subsection{Train speed}

To obtain the wind pressure at different train speeds, the wind pressure of the bottom plate, "a-di-1", is fitted at different train speeds. The fitting formula $P=a v^{b}$ is adopted, where $P$ is the pressure extremum. The fitting relationship is described in Table 1.

To investigate the bridge dynamic responses under wind, the lift force, drag force, and torsion moment can be introduced to evaluate the loads applied on the bridge girder (Yan et al. 2014). As an example, the lift force applied on the beam section is discussed herein. Figure $7 \mathrm{a}$ and $\mathrm{b}$ plot the aerodynamic curves at different train speeds. The time history of each beam section is basically consistent at different train speeds. As the 


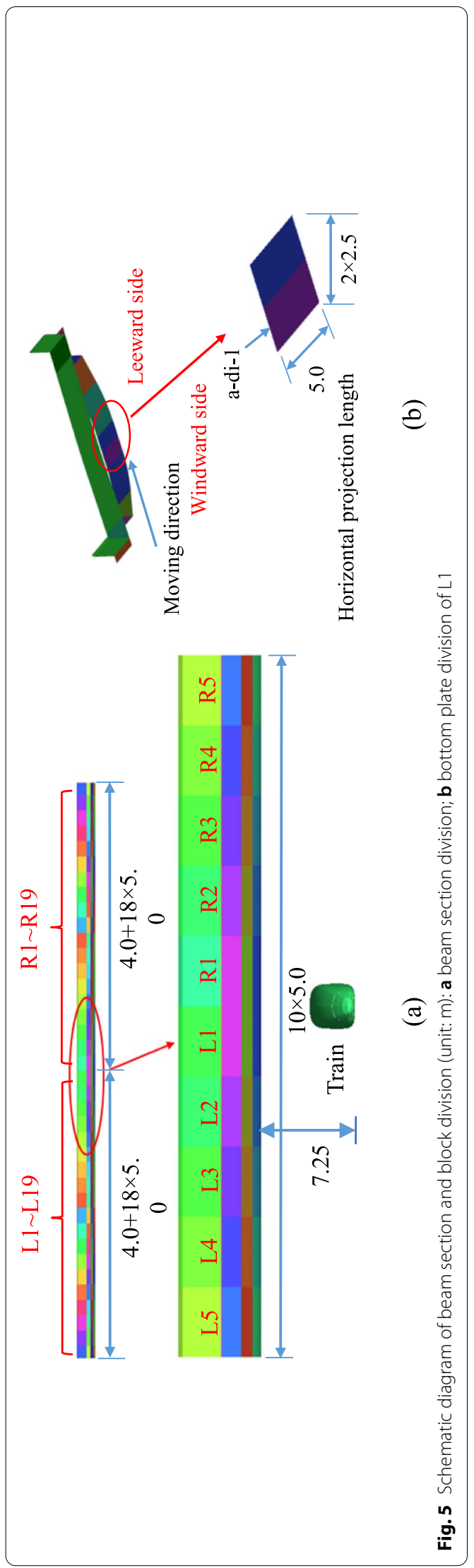




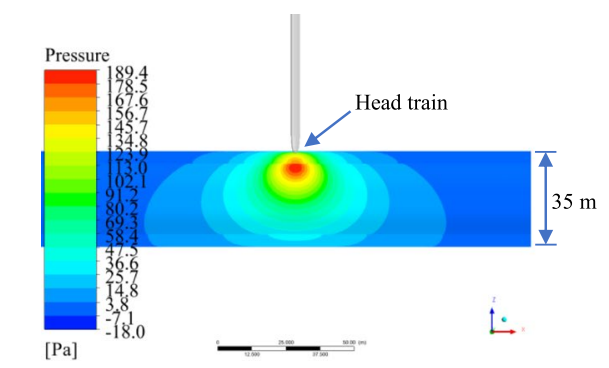

(a)

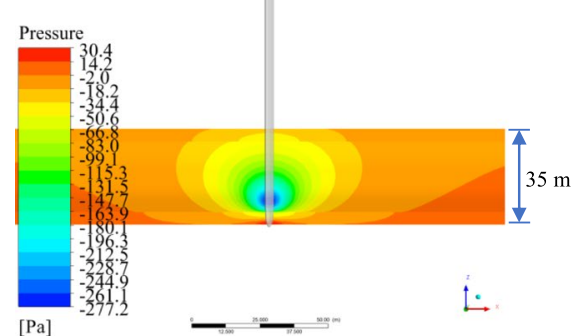

(c)

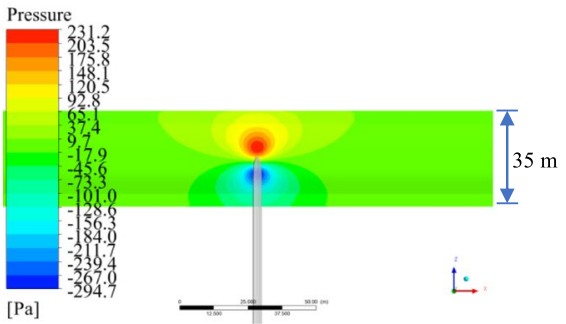

(e)

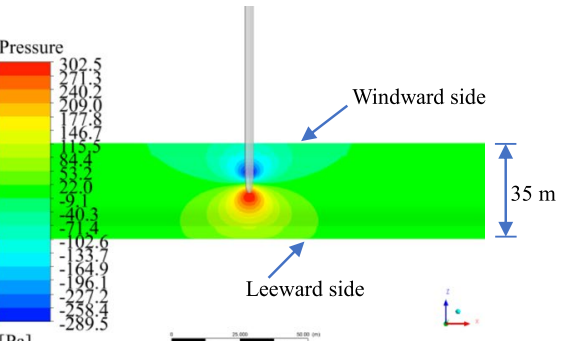

(b)

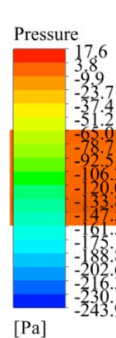

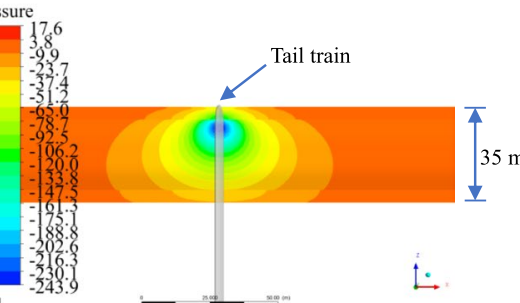

(d)

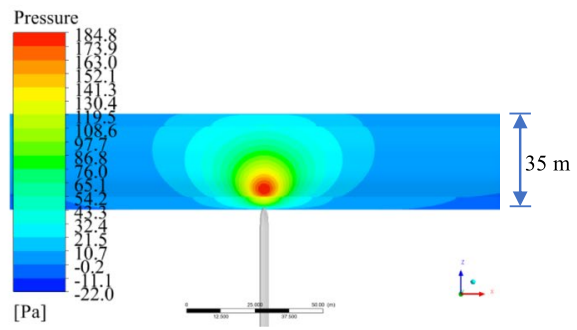

(f)

Fig. 6 Wind pressure nephogram: a nose of head carriage reaches the windward side; $\mathbf{b}$ nose of head carriage reaches the center line of the girder; $\mathbf{c}$ nose of head carriage reaches the leeward side; $\mathbf{d}$ nose of tail carriage reaches the windward side; $\mathbf{e}$ nose of tail carriage reaches the center line of the girder; $\mathbf{f}$ nose of tail carriage reaches the leeward side

Table 1 Positive extremum and negative extremum of "head wave" and "tail wave" of bottom plate at different train speeds

\begin{tabular}{|c|c|c|c|c|c|c|c|}
\hline \multirow[t]{2}{*}{ Item } & \multicolumn{5}{|c|}{$\begin{array}{l}\text { Wind extremum of bottom plate at different train } \\
\text { speeds }(\mathrm{Pa})\end{array}$} & \multirow[t]{2}{*}{$\begin{array}{l}\text { Correlation } \\
\text { relation } P\end{array}$} & \multirow{2}{*}{$\begin{array}{l}\text { Correlation } \\
\text { coefficient } \\
R^{2}\end{array}$} \\
\hline & $200 \mathrm{~km} / \mathrm{h}$ & $250 \mathrm{~km} / \mathrm{h}$ & $300 \mathrm{~km} / \mathrm{h}$ & $350 \mathrm{~km} / \mathrm{h}$ & $400 \mathrm{~km} / \mathrm{h}$ & & \\
\hline $\begin{array}{l}\text { Positive } \\
\text { extremum of } \\
\text { "head wave" }\end{array}$ & 88 & 137 & 196 & 269 & 349 & $P=0.0023 v^{1.9912}$ & 0.9999 \\
\hline $\begin{array}{l}\text { Positive } \\
\text { extremum of "tail } \\
\text { wave" }\end{array}$ & -93 & -145 & -207 & -284 & -374 & $P=0.0016 v^{2.0147}$ & 1 \\
\hline $\begin{array}{l}\text { Negative } \\
\text { extremum of } \\
\text { "head wave" }\end{array}$ & -92 & -143 & -207 & -281 & -366 & $P=-0.0020 v^{2.0296}$ & 0.9999 \\
\hline $\begin{array}{l}\text { Negative } \\
\text { extremum of "tail } \\
\text { wave" }\end{array}$ & 70 & 110 & 159 & 217 & 284 & $P=-0.0024 v^{1.9946}$ & 1 \\
\hline
\end{tabular}




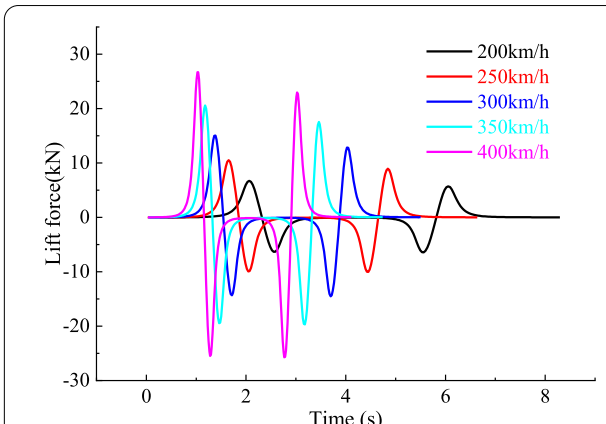

(a)

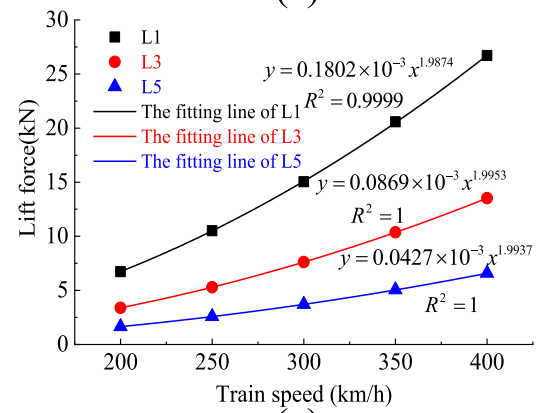

(c)

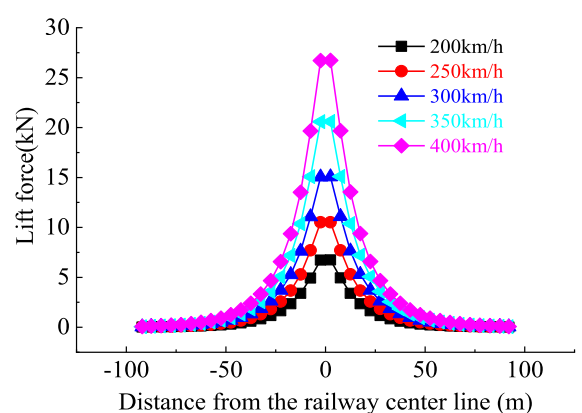

(b)

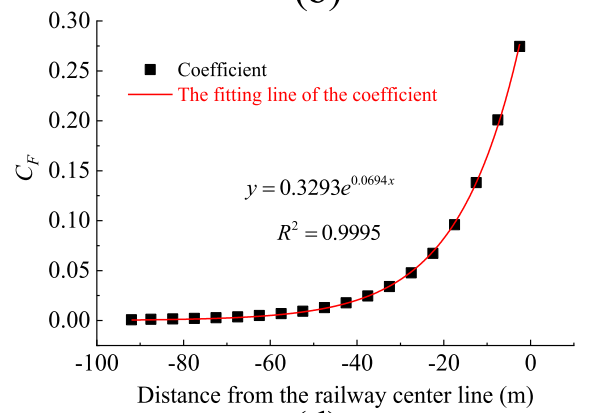

(d)

Fig. 7 Effects of train speeds: a lift force time history curve; $\mathbf{b}$ attenuation curve of positive lift force of head wave along longitudinal bridge direction; c variation of positive lift force extremum of head wave in $L 1, L 3, L 5$ with train speed; $\mathbf{d}$ head wave lift force positive extremum coefficient along longitudinal bridge direction

train speed increases, the extremum increases rapidly. The time differences between the head and tail waves and the time differences between the positive and negative pressure extrema of the head and tail waves become significantly shorter, and the shortening time decreases as the train speed increases. The attenuation trend of the extreme lift force along the longitudinal bridge direction at different train speeds is basically unchanged, and decreases as the distance increases. A faster train speed produces a more rapid decay in the lift force along the longitudinal bridge direction.

To explore the relationship between the lift force extremum and train speed, curve fitting is applied to the head wave lift force positive extremum of each beam section and the train speed. Examples for beams L1, L3, and L5 are shown in Fig. 7c. The functional relation between the positive lift force extremum $F$ and train speed $v$ is expressed as $F=a v^{b}$, where $a$ and $b$ are fitting parameters and $v$ is given in $\mathrm{km} / \mathrm{h}$. The correlation coefficient $R^{2}$ is close to 1 , indicating that the fitting results are fairly good. The power exponent is close to 2 , indicating that the relationship between the lift force and speed is quadratic.

Furthermore, to study the functional relationship between the lift force extrema of the beam sections and the distance from the track centerline, we now introduce the lift force extremum coefficient $C_{F}$. The formula for the positive lift force extremum can be expressed as $F=0.5 C_{F} \rho v^{2}$, where the air density $\rho$ is $1.225 \mathrm{~kg} / \mathrm{m}^{3}$.

Figure $7 \mathrm{~d}$ shows the attenuation of $C_{F}$ along the longitudinal bridge direction. $C_{F}$ and the distance from the track centerline have been fitted by a power exponent according to the functional expression $C_{F}=a e^{b x}$, where $a$ and $b$ are the fitting parameters and $x$ is 
the distance from the track centerline in meters. $R^{2}$ is close to 1 , which means the fitting results are fairly good. Therefore, $C_{F}$ has a power exponential relationship with the distance from the track centerline.

\subsection{Clearance under bridge}

To obtain the wind pressure at different clearances under the bridge, the wind pressure of the bottom plate "a-di-1" is fitted at different bridge clearances. The fitting formula is $P=a h^{b}$, and the fitting relationship is described in Table 2 .

Figure $8 \mathrm{a}$ and $\mathrm{b}$ plot the aerodynamic curves at different clearances under the bridge. The results reveal that, at different clearance levels, the lift force time history of each beam section is basically consistent, and the occurrence times of the extrema are largely unchanged. However, as the clearance under the bridge decreases, the extreme values increase sharply, and smaller clearance levels produce greater increases in amplitude. The attenuation trend of the extreme lift force along the longitudinal bridge direction is broadly consistent. A smaller clearance under the bridge results in more rapid decay in the lift force extremum along the longitudinal bridge direction.

Figure 8c shows the fitting curve of the positive lift force extremum for the head waves at beams L1, L3, and L5 with respect to the clearance under the bridge. The positive extremum of the head wave lift force has a negative power exponential relationship with the clearance under the bridge, and the functional relation can be expressed as $F=a h^{b}$, where $a$ and $b$ are fitting parameters and $h$ is the clearance under the bridge in meters. $R^{2}$ is close to 1 , which means the fitting results are fairly good. The power exponent $b$ decreases from -1.3129 for beam L1 to -0.8479 for beam L5. Therefore, there is a negative power exponential relationship between the lift force extremum of the beam section and the clearance under the bridge, but the exponents are different. Farther away from the track centerline, the absolute value of the exponent becomes smaller.

\subsection{Intersection angle}

Figure 9 shows the aerodynamic curves at different intersection angles. The time history curves of the lift force on each beam section at different intersection angles exhibit little variation. Along the longitudinal bridge direction, the lift force extrema at both the side- and mid-span beams are hardly affected by changes in the

Table 2 Positive extremum and negative extremum of "head wave" and "tail wave" of bottom plate for different clearances

\begin{tabular}{|c|c|c|c|c|c|c|c|}
\hline \multirow[t]{2}{*}{ Item } & \multicolumn{5}{|c|}{$\begin{array}{l}\text { Wind extremum of bottom plate at } \\
\text { different train speeds }(\mathrm{Pa})\end{array}$} & \multirow[t]{2}{*}{ Correlation relation $P$} & \multirow{2}{*}{$\begin{array}{l}\text { Correlation } \\
\text { coefficient } \\
R^{2}\end{array}$} \\
\hline & $5.25 \mathrm{~m}$ & $7.25 \mathrm{~m}$ & $9.25 \mathrm{~m}$ & $11.25 \mathrm{~m}$ & $13.25 \mathrm{~m}$ & & \\
\hline $\begin{array}{l}\text { Positive extremum of } \\
\text { "head wave" }\end{array}$ & 467 & 269 & 169 & 114 & 82 & $P=9567 h^{-1.8174}$ & 0.9985 \\
\hline $\begin{array}{l}\text { Positive extremum of } \\
\text { "tail wave" }\end{array}$ & -555 & -284 & -174 & -116 & -82 & $P=5525 h^{-1.6523}$ & 0.9972 \\
\hline $\begin{array}{l}\text { Negative extremum of } \\
\text { "head wave" }\end{array}$ & -510 & -281 & -169 & -115 & -81 & $P=-16890 h^{-2.0597}$ & 1 \\
\hline $\begin{array}{l}\text { Negative extremum of } \\
\text { "tail wave" }\end{array}$ & 354 & 217 & 142 & 98 & 72 & $P=-12780 h^{-1.9399}$ & 0.9991 \\
\hline
\end{tabular}




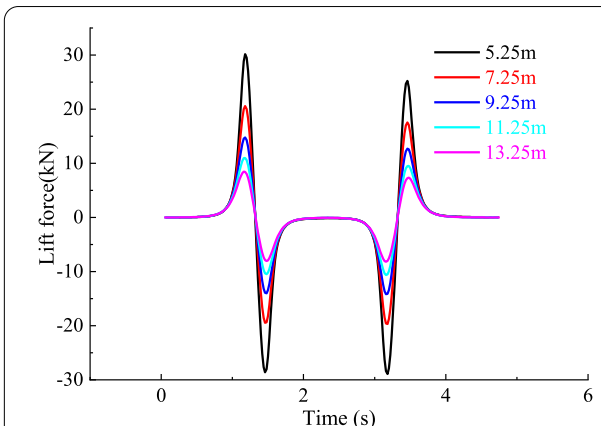

(a)

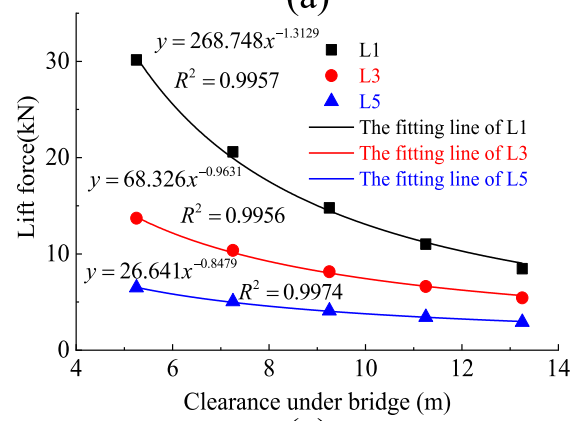

(c)

Fig. 8 Effects of clearance under bridge: a lift force time history curve; $\mathbf{b}$ attenuation curve of positive lift force of head wave along longitudinal bridge direction; c variation of positive lift force extremum of head wave in $L 1, L 3, L 5$ with train speed

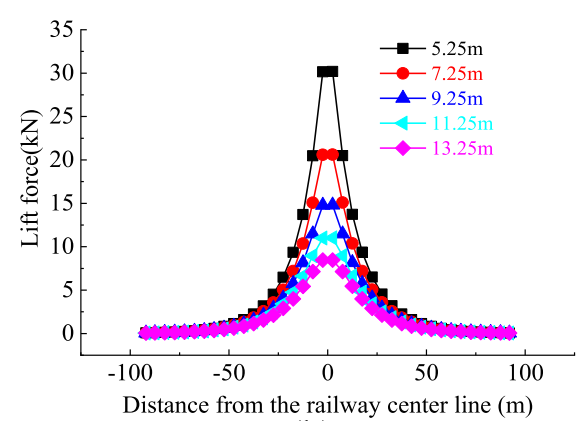

(b)

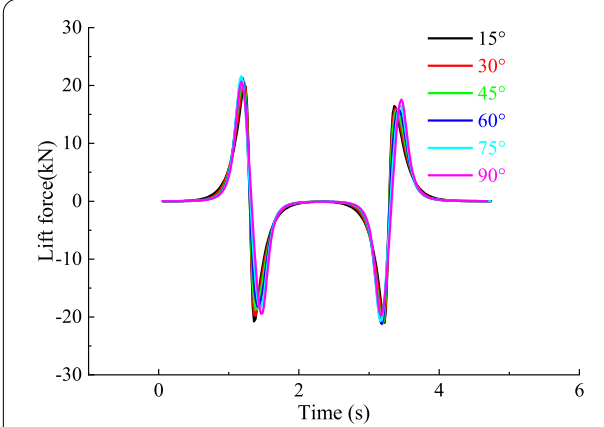

(a)

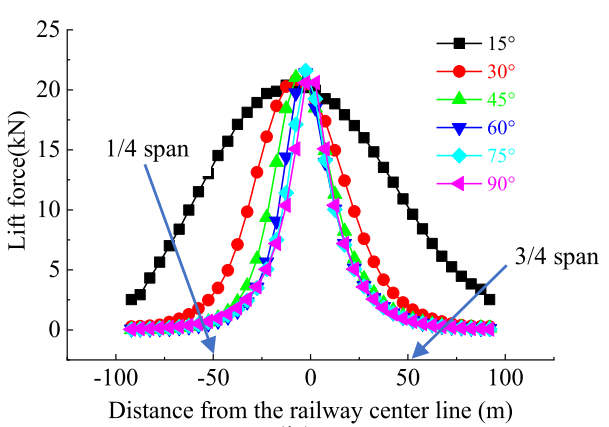

(b)

Fig. 9 Effects of angle of intersection: a lift force time history curve; $\mathbf{b}$ attenuation curve of positive lift force of head wave along longitudinal bridge direction

intersection angle, while those at the 1/4-span and 3/4-span beams are more strongly affected. This is because, as the intersection angle decreases, the distance between the mid-span beam and the track centerline changes little, and so the angle change has little impact. For both side-span beams, although the distance from the track centerline changes more, shifting the angle within the range $15-90^{\circ}$ means that the side span is still far from the track centerline, and is therefore outside the main influence range of train-induced wind. For the 1/4-span and 3/4-span beam sections, the distances from the track centerline change significantly and these regions are within the main influence range of train-induced wind, so the lift force extremum changes considerably. At 
smaller intersection angles, the lift force extremum exhibits greater changes with the intersection angle.

\subsection{Simplified aerodynamic load model}

As a guide for engineering practice, Fig. 10 presents a simplified diagram of the wind pressure curve at bottom plate "a-di-1". In the figure, $l_{\text {head }}$ and $l_{\text {tail }}$ are the train running distances between the positive and negative extrema of head wave and tail wave, respectively, $P_{\text {head }}(+)$ and $P_{\text {head }}(-)$ are the positive and negative pressure extrema of the head wave, respectively, $P_{\text {tail }}(+)$ and $P_{\text {tail }}(-)$ are the positive and negative pressure extrema of the tail wave, respectively, $K_{\text {head }}$ is the slope between the positive and negative extrema of the head wave, and $K_{\text {before head }}, K_{\text {after head }}$ are the slopes before the positive extremum and after the negative extremum of the head wave, respectively. When calculating $K_{\text {before }}$ head and $K_{\text {after head }}$, the slope of the connecting line between the wind pressure extremum and the $1 / 3$ wind pressure extremum is taken as the wind pressure slope before and after extrema. $K_{\text {tail }}, K_{\text {before tail }}$ and $K_{\text {after tail }}$ are defined similarly.

The train considered in this study is the CRH380 type. The wind pressure extrema $P_{\text {head }}(+), P_{\text {head }}(-), P_{\text {tail }}(+)$, and $P_{\text {tail }}(-)$ can be calculated by the above fitting formulas. The wind pressure models of the bottom plate at different train speeds and different clearances under the bridge are now studied.

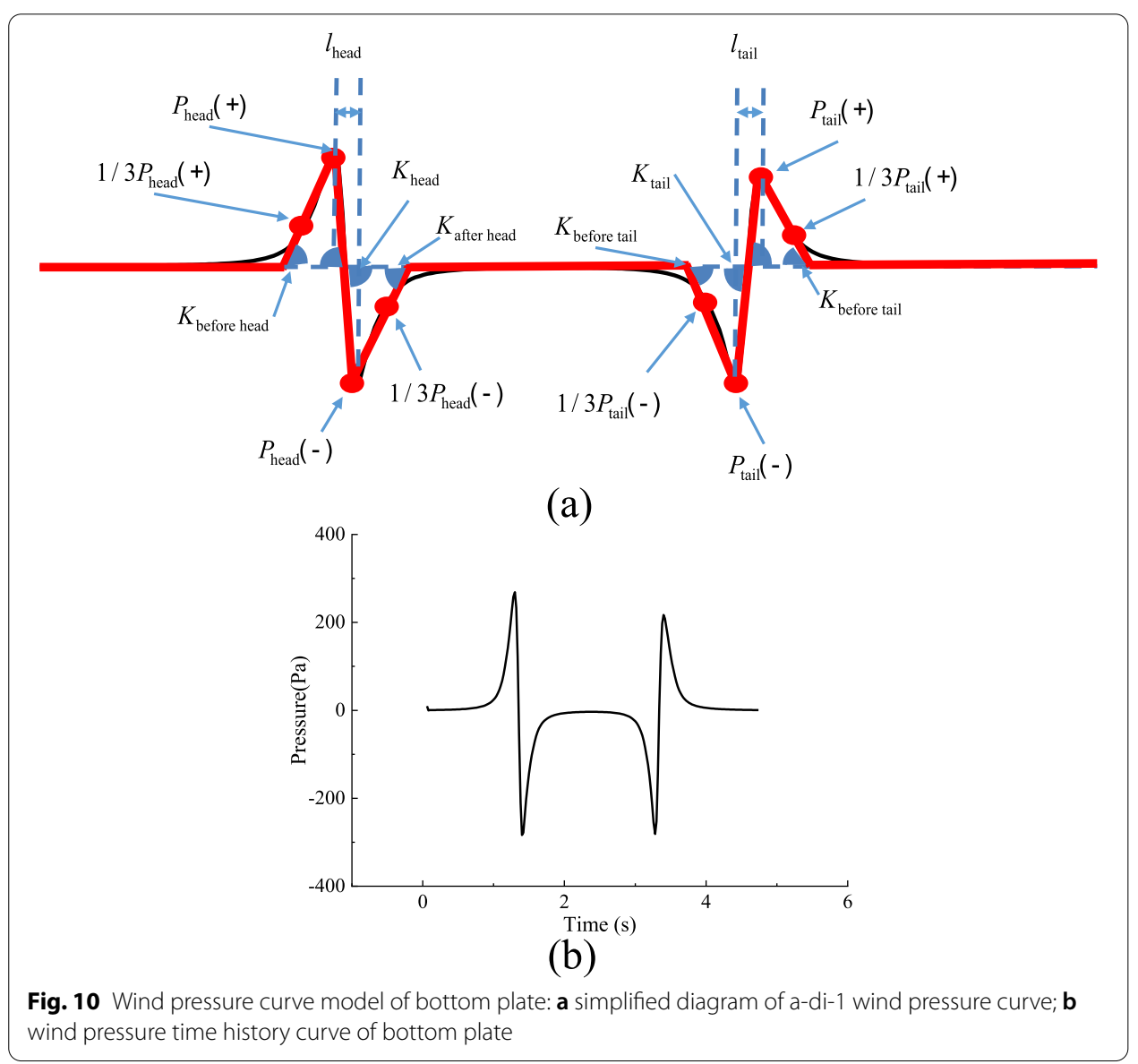


The parameters at different train speeds are listed in Table 3(a). The clearance under the bridge is $7.25 \mathrm{~m}$ and the intersection angle is $90^{\circ}$. As the train speed changes, the parameters of the wind pressure curve exhibit little variation.

The parameters at different clearances under the bridge are given in Table 3(b). The train speed is $350 \mathrm{~km} / \mathrm{h}$ and the intersection angle is $90^{\circ}$. There is a big difference in $l_{\text {head }}$ and $l_{\text {tail }}$, which is mainly caused by the pressure wave pattern generated by the train. In the direction of train height, the distance between the positive and negative extrema increases with distance from the train.

The generalized wind pressure curve model shown in Fig. 10a and the corresponding parameter values listed in Table 3 can be jointly regarded as a "load spectrum". The "load spectrum" is useful for other bridges with similar scenarios. Nevertheless, when other conditions change drastically (e.g., girder section, train type), the specific parameter values should be carefully checked.

\section{Bridge responses in different stages}

\subsection{Evaluation indexes}

The FE model of the bridge was established using the MIDAS/Civil software and the dynamic response of the bridge was analyzed in the construction and operation stages. The stay cable was simulated by a bar element, and the tower, girder, and beam were simulated by beam elements. The structure was discretized based on the theoretical completed bridge alignment, and the calculation diagram for the cantilever stage before closure and the operation stage were formed according to the erection process, as shown in Fig. 11. The number of elements and nodes in the cantilever stage were 191 and 221, respectively, and the number of elements and nodes in the operation stage were 243 and 388, respectively. The first five natural vibration modes and frequencies are shown in Fig. 12. Based on the aerodynamic loads aforementioned (e.g., Figs. 7a, 8a, and 9a), the time-varying nodal forces were applied on the FE model. Note that the nodal forces

Table 3 Wind pressure curve parameters: (a) different train speeds; (b) different clearances under bridge

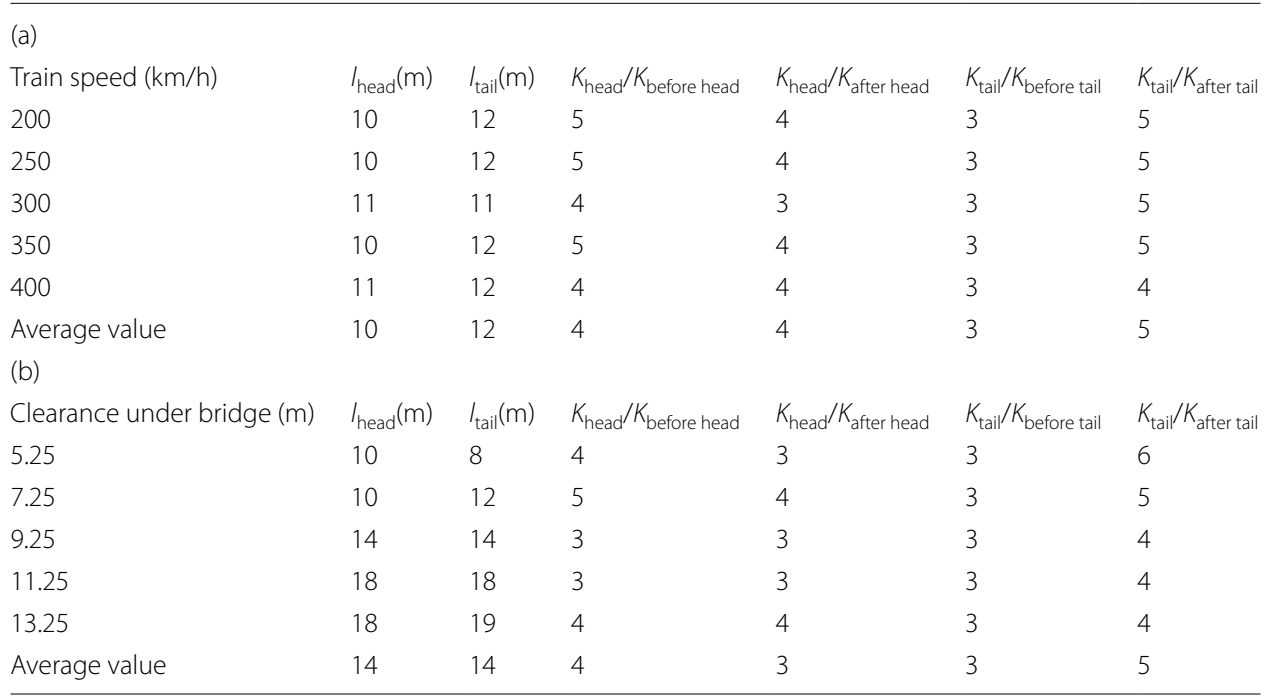




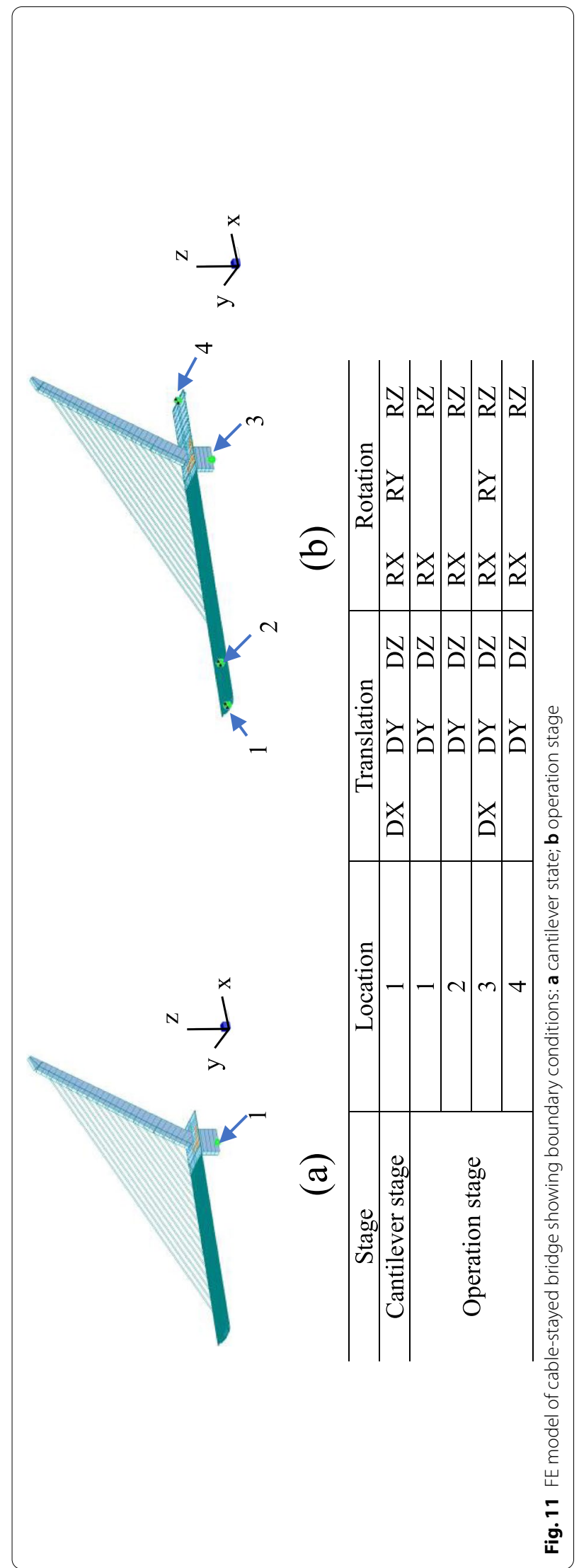


(a)
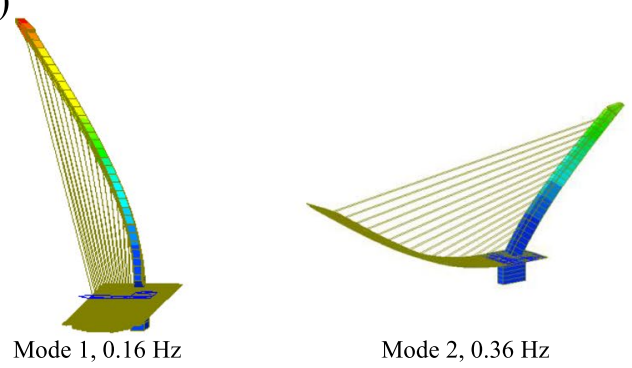

Mode 2, $0.36 \mathrm{~Hz}$

Mode 3, $0.61 \mathrm{~Hz}$

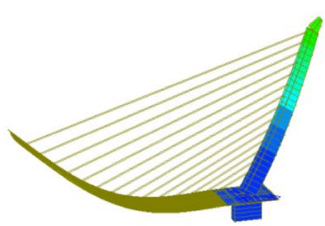

(b)

Mode 4, $0.68 \mathrm{~Hz}$

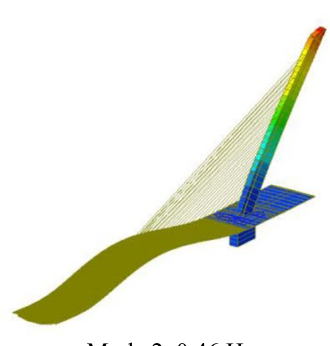

Mode $5,0.86 \mathrm{~Hz}$

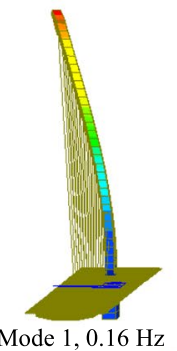

Mode $2,0.46 \mathrm{~Hz}$

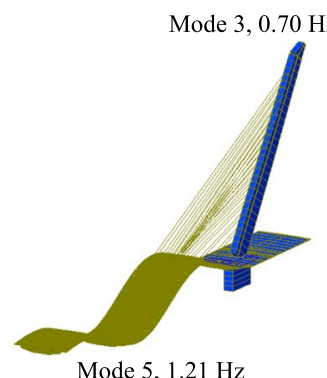

Mode 4, $0.88 \mathrm{~Hz}$

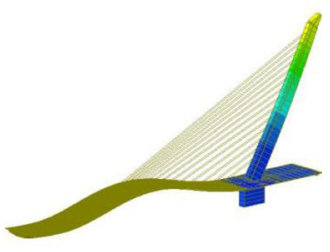

ode $5,1.21 \mathrm{~Hz}$

Fig. 12 Natural vibration frequency of the first five modes: a cantilever state; $\mathbf{b}$ operation stage

include three components, i.e., lift force, drag force, and torsion moment. The direct integration method was used based on a time step of $0.001 \mathrm{~s}$. A damping ratio of $1 \%$ was adopted for the dynamic response calculation.

The rotation construction of the bridge was planned to be carried out during the "skylight" time. After the rotation had been completed, the main span was supported on the temporary pier. The position of the closure segment is shown in Fig. 13. Before closure, the temporary pier was supported at the diaphragm. To avoid the temporary pier from being subjected to large forces and adversely affecting the steel beams, the total counterforce of the temporary pier should not exceed $2000 \mathrm{kN}$. Calculations indicate that the negative counter-force limit is $300 \mathrm{kN}$.

As the bridge is equipped with sidewalks, the beam vibration caused by train-induced aerodynamic action may reduce the comfort of pedestrians. Therefore, it is necessary 


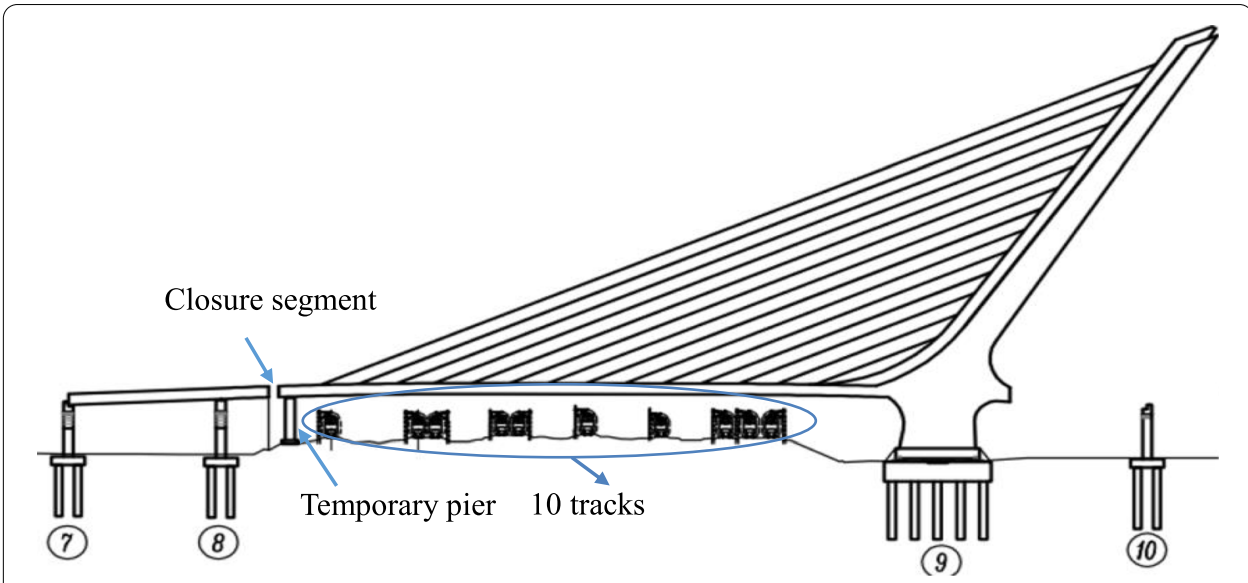

Fig. 13 Location of closure and temporary pier

to research the bridge comfort level in the operation stage. In this paper, the German EN03 standard (Butz et al. 2008) is adopted to evaluate the comfort, and the evaluation indexes are presented in Table 4. Due to the special working condition in which the beam falls on the temporary pier and is temporarily not closed, this section analyzes the vibration displacement and acceleration of the cable-stayed bridge during the cantilever state (conservative consideration) and the operation stage, as well as the supporting counter-force when the main beam falls on the temporary pier (with vertical constraints) and the comfort during the operation stage under the train-induced aerodynamic force. The specific evaluation indexes of each stage are listed in Table 5.

\subsection{Construction stage}

For the construction stage, when the track centerline is arranged near the beam end, only the aerodynamic force on one side of the track centerline is exerted on the beam

Table 4 Suggested comfort value of German EN03 standard

\begin{tabular}{llll}
\hline Comfort class & Degree of comfort & $\begin{array}{l}\text { Vertical acceleration } \\
\left(\mathbf{m} / \mathbf{s}^{2}\right)\end{array}$ & $\begin{array}{l}\text { Lateral } \\
\text { acceleration } \\
\left(\mathbf{m} / \mathbf{s}^{2}\right)\end{array}$ \\
\hline $\mathrm{CL1}$ & Maximum & $<0.50$ & $<0.10$ \\
$\mathrm{CL2}$ & Medium & $0.50 \sim 1.00$ & $0.10 \sim 0.30$ \\
$\mathrm{CL3}$ & Minimum & $1.00 \sim 2.50$ & $0.30 \sim 0.80$ \\
$\mathrm{CL4}$ & Unacceptable discomfort & $>2.50$ & $>0.80$ \\
\hline
\end{tabular}

Table 5 Evaluation index of bridge dynamic response in each stage

\begin{tabular}{llll}
\hline Stage & $\begin{array}{l}\text { Vibration displacement and } \\
\text { acceleration }\end{array}$ & $\begin{array}{l}\text { Counter-force of the } \\
\text { temporary pier }\end{array}$ & Comfort level \\
\hline $\begin{array}{l}\text { Construction stage, girder has } \\
\text { not fallen on the temporary } \\
\text { pier }\end{array}$ & $\sqrt{ }$ & $\times$ & $\times$ \\
$\begin{array}{l}\text { Construction stage, girder falls } \\
\text { on the temporary pier }\end{array}$ & $\times$ & $\sqrt{ }$ & $\times$ \\
\begin{tabular}{l} 
Operation stage \\
\hline
\end{tabular} & $\sqrt{ }$ & $\times$ & $\sqrt{ }$ \\
\hline
\end{tabular}


body, and thus the dynamic response of the beam is less than the maximum at this time. According to our calculations, the beam end suffers the maximum vertical displacement when the distance between the track centerline and the beam end is about four beam sections (approximately $20 \mathrm{~m}$ ). Therefore, in the construction stage, the track centerline is about four beam sections away from the beam end, i.e., it is regarded as the extreme scenario. The scenarios of multiple presence of trains are not considered since they are rare.

\subsubsection{Influence of train speed}

Figure 14 shows the bridge dynamic response at different train speeds. As the train speed increases, the maximum values of the vibration displacement, acceleration, and counter-force of the temporary pier basically show an upward trend. The different trends for individual speeds are mainly due to the following reasons:

(1) As higher speeds will enhance the fluctuations in the lift time history curve, the time difference between positive and negative extrema becomes shorter, resulting in a faster unidirectional acceleration time for the beam. Increases in the train speed and the resulting increase in the lift extremum aggravate the vibration of the beam, but the reduction in the unidirectional force action time weakens the beam vibration. Therefore, increasing the train speed may not aggravate the beam vibration.

(2) The vertical vibration modes mainly include the second-order natural vibration mode $(0.36 \mathrm{~Hz})$ and the fourth-order natural vibration mode $(0.68 \mathrm{~Hz})$. As the train speed changes, the disturbance frequency of the train-induced wind also changes.

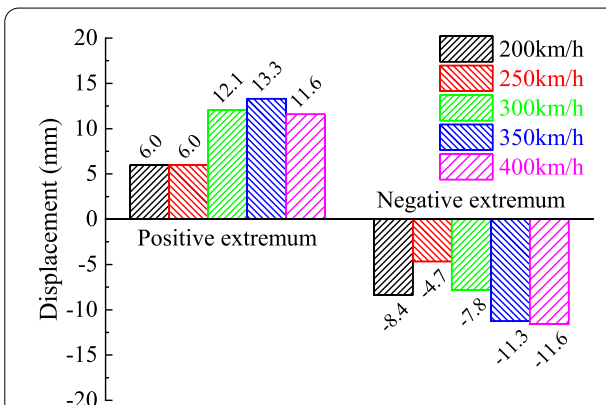

(a)

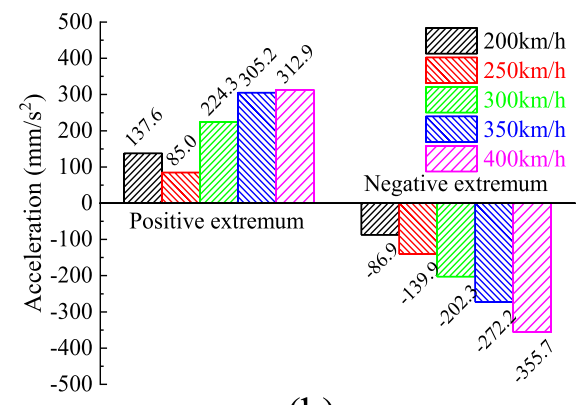

(b)

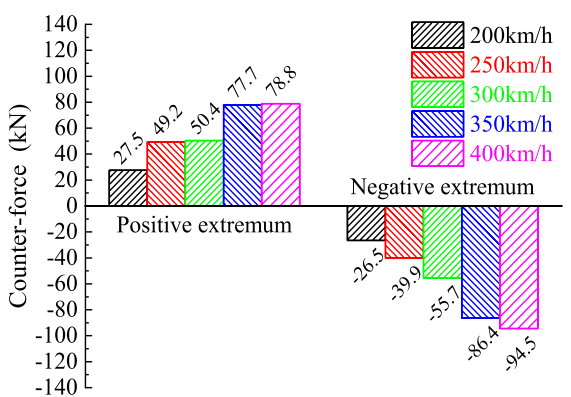

(c)

Fig. 14 Girder dynamic response at different train speeds in construction stage: a maximum displacement value; $\mathbf{b}$ maximum acceleration value; $\mathbf{c}$ maximum counter-force of the temporary pier 
Therefore, the contribution ratio of each natural vibration mode to the response varies at different train speeds, and so an increase in the train speed may not aggravate the beam vibration.

\subsubsection{Influence of clearance under bridge}

Figure 15 shows the bridge dynamic response at different clearances under the bridge. As the clearance under the bridge decreases, the maximum vibration displacement, acceleration, and counter-force of the temporary pier increase to different degrees, with the rate of increase being greater at smaller clearance levels. For example, as the clearance under the bridge decreases uniformly from $13.25 \mathrm{~m}$ to $5.25 \mathrm{~m}$, the maximum vibration displacement of the beam end initially increases by $1.2 \mathrm{~mm}$ and eventually increases by $2.6 \mathrm{~mm}$.

\subsubsection{Influence of intersecting angle}

Figure 16 shows the bridge dynamic response at different intersection angles. In general, a decrease in the intersection angle causes the vibration displacement to increase, but the variations in the vibration acceleration and maximum counter-force of the temporary pier are irregular. This is mainly because, at smaller intersection angles, the influence range of the "positive-negative-negative-positive" pressure wave of the head and tail of the train widens as the train passes along the beam, which intensifies the disturbance to the beam body. However, changes to the fluctuating wind frequency and the inconsistent stress time of different beam sections complicate the beam vibration.

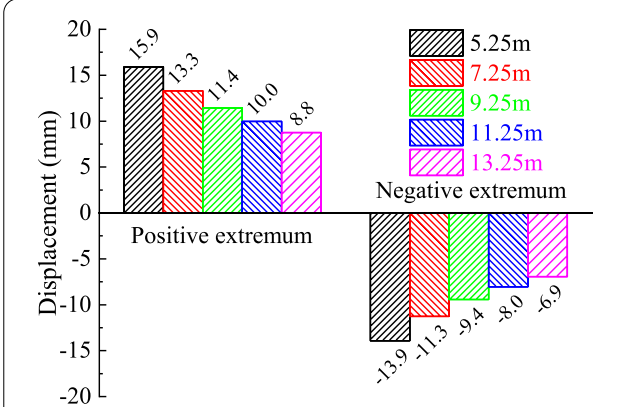

(a)

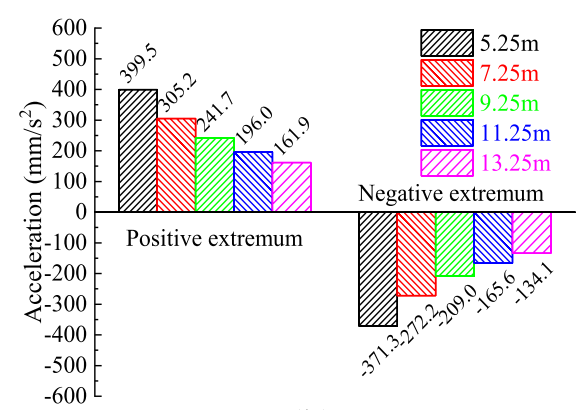

(b)

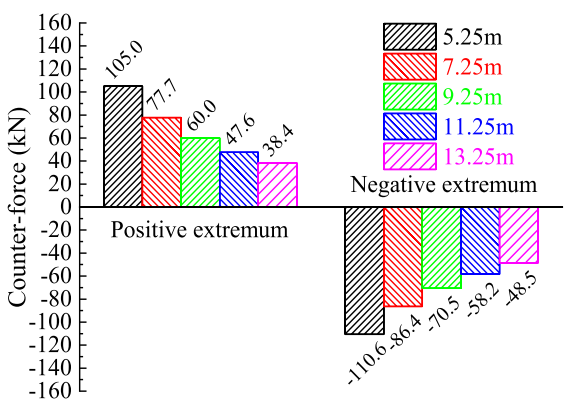

(c)

Fig. 15 Girder dynamic response at different clearances under bridge in construction stage: a maximum displacement value; $\mathbf{b}$ maximum acceleration value; $\mathbf{c}$ maximum counter-force of the temporary pier 


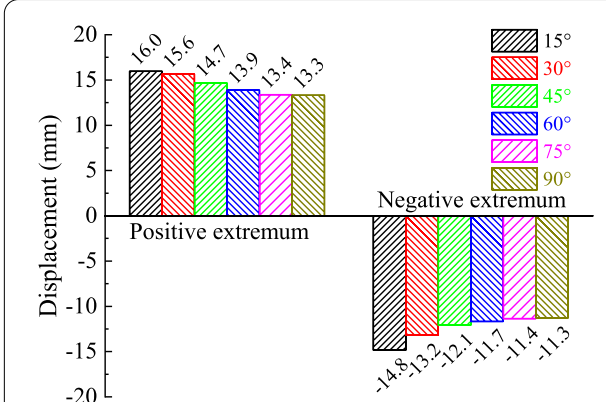

(a)

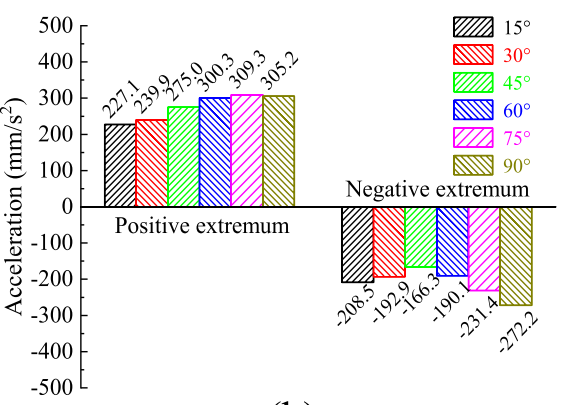

(b)

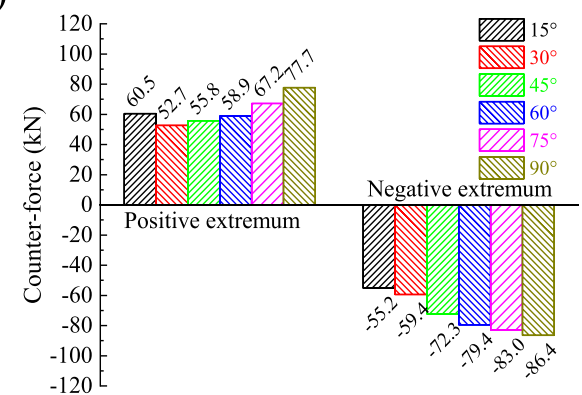

(c)

Fig. 16 Girder dynamic response at different angles of intersection in construction stage: a maximum displacement value; $\mathbf{b}$ maximum acceleration value; $\mathbf{c}$ maximum counter-force of the temporary pier

Within the parameter ranges investigated in this paper, the absolute values of the maximum vertical vibration displacement and acceleration of the beam are within $4-16 \mathrm{~mm}$ and $85-400 \mathrm{~mm} / \mathrm{s}^{2}$, respectively, in the construction stage. The influence of train-induced wind on the steel box-girder of the closure segment is limited. Moreover, the extreme values of the positive counter-force are less than $105 \mathrm{kN}$, which is negligible compared with the maximum limit of $2000 \mathrm{kN}$. The absolute values of the negative counter-force are less than $300 \mathrm{kN}$, which will not cause the temporary pier to void.

\subsection{Operation stage}

During the operation stage, the track centerline is arranged at the mid-span position. Through comparative analysis, it is found that the maximum bridge responses can be obtained in this scenario. The scenarios of multiple presence of trains are not considered. In the operation stage, the influence of train speed, clearance under the bridge, and train-bridge intersection angle on the vibration displacement and acceleration of the beam are basically the same as in the construction stage. Within the parameter ranges investigated in this paper, the absolute values of the maximum vertical vibration displacement and acceleration of the beam are within $1-5 \mathrm{~mm}$ and $42-174 \mathrm{~mm} / \mathrm{s}^{2}$, respectively, in the operation stage. Compared with the construction stage, the displacement and acceleration of beam decrease, which is mainly because of the stronger bridge boundary constraints and greater total stiffness.

According to the definition of comfort in the German EN03 standard, the vertical acceleration of the beam during single line operation is less than $0.50 \mathrm{~m} / \mathrm{s}^{2}$, which is classified as "very comfortable." Therefore, within the parameter ranges investigated 
in this paper, the beam vibration caused by train-induced aerodynamic action will not affect pedestrian comfort.

\section{Conclusions}

Based on FE numerical simulations of a steel box-girder cable-stayed bridge, this paper has investigated the aerodynamic characteristics of high-speed trains passing through a bridge. The influence of the train speed, clearance under the bridge, and train-bridge intersection angle was considered, and the bridge dynamic response during construction and operation stage was studied. The main conclusions can be summarized as follows:

(1) The wind pressure on the bottom plate and the beam lift extremum have a quadratic relationship with the train speed and a negative power exponential relationship with the clearance under the bridge. At different intersection angles, the lift amplitude at both the side-span beam and the mid-span beam section is less affected than at the 1/4-span and 3/4-span beams.

(2) The bridge dynamic responses in the construction and operation stages are basically the same under the different influencing factors. As the train speed increases and the clearance under the bridge decreases, the vibration displacement, acceleration, and maximum counter-force of the temporary pier basically exhibit an upward trend. As the intersection angle decreases, the vibration displacement generally increases, but the variations in the vibration acceleration and the maximum counter-force of the temporary pier do not exhibit clear trends. A simplified aerodynamic load model has been developed to guide engineering practice, and wind pressure models of the bottom plate at different train speeds and different clearances under the bridge were summarized.

(3) Within the parameter ranges investigated in this paper, the absolute values of the maximum vertical vibration displacement and acceleration of the beam were found to be within $4-16 \mathrm{~mm}$ and $85-400 \mathrm{~mm} / \mathrm{s}^{2}$, respectively, in the construction stage. The influence of train-induced wind on the steel box-girder of the closure segment was found to be limited. During the operation stage, the absolute values of the maximum vertical vibration displacement and acceleration of the beam were within $1-5 \mathrm{~mm}$ and $42-174 \mathrm{~mm} / \mathrm{s}^{2}$, respectively. Compared with the construction stage, the dynamic response of the beam was significantly decreased by the larger overall stiffness and the constraints of the support.

(4) Within the parameter ranges investigated in this paper, the absolute values of the positive counter-force of the main girder falling on the temporary pier after turning were less than $105 \mathrm{kN}$, which is negligible compared with the maximum limit of $2000 \mathrm{kN}$. The absolute values of the negative counter-force were less than $300 \mathrm{kN}$, which will not cause the temporary pier to void.

(5) Within the parameter ranges investigated in this paper, the beam vertical acceleration during the operation stage was less than $0.50 \mathrm{~m} / \mathrm{s}^{2}$, which is classified as "very comfortable." Therefore, the beam vibration caused by train-induced aerodynamic action will not have a significant impact on pedestrian comfort. 
The main results of this study are obtained based on CFD simulations. Nevertheless, the presented results themselves are believed to be conceptually true in terms of their prediction insights concerning the overall performance of the specific case from an engineering perspective. The instrumentation plan, loading scheme, the anticipated wind pressures and structural responses in the upcoming field test will be mainly based on the findings of this article.

\section{Abbreviations}

LES: Large eddy simulation; CFD: Computational fluid dynamics; FE: Finite element; DNS: Direct numerical simulation; RANS: Reynolds-averaged Navier-Stokes.

\section{Acknowledgments}

Not applicable.

\section{Authors' contributions}

ZL: Formal analysis, Investigation, Writing - original draft. XZ: Conceptualization, Supervision, Writing - review \& editing, Funding acquisition. TC: Validation. YL: Data curation. BL: Software. All authors read and approved the final manuscript.

\section{Funding}

This work was supported financially by the National Nature Science Foundation of China (Grant Nos. 51778534, 51978580)

Availability of data and materials

The data and materials in current study are available from the corresponding author on reasonable request.

\section{Declarations}

Competing interests

The authors declare that they have no competing interests.

Received: 1 October 2021 Accepted: 16 December 2021

Published online: 22 January 2022

\section{References}

Baker C, Jordan S, Gilbert T, Quinn A, Sterling M, Johnson T, Lane J (2014) Transient aerodynamic pressures and forces on trackside and overhead structures due to passing trains. Part 1: model-scale experiments; Part 2: standards applications. Proc Inst Mech Eng Part F J Rail Rapid Transit 228(1):37-70

Baker CJ, Brockie NJ (1991) Wind tunnel tests to obtain train aerodynamic drag coefficients: Reynolds number and ground simulation effects. J Wind Eng Ind Aerodyn 38:23-28

Bell JR, Burton D, Thompson MC, Herbst AH, Sheridan J (2015) Moving model analysis of the slipstream and wake of a high-speed train. J Wind Eng Ind Aerodyn 136:127-137

Bouras L, Ma L, Ingham D, Pourkashanian M (2018) An improved k- $\omega$ turbulence model for the simulations of the wind turbine wakes in a neutral atmospheric boundary layer flow. J Wind Eng Industrial Aerodyn 179:358-368

Bruno L, Coste N, Fransos (2012) Simulated flow around a rectangular 5:1 cylinder: Spanwise discretisation effects and emerging flow features. J Wind Eng Industrial Aerodyn 104-106:203-215

Butz C, Heinemeyer C, Keil A (2008) Human induced vibrations of steel structures: design of footbridges guideline (RFS2CT-2007-00033). Brussels: Research Fund for Coal and Steel

Devolder B, Troch P, Rauwoens P (2018) Performance of a buoyancy-modified k- $\omega$, and k- $\omega$ SST turbulence model for simulating wave breaking under regular waves using OpenFOAM. Coast Eng 138:49-65

Gerhardt HJ, Krüger O (1998) Wind and train driven air movements in train stations. J Wind Eng Ind Aerodyn 74-76:589-597

Hemida H, Krajnović S (2009) LES study of the influence of the nose shape and yaw angles on flow structures around trains. J Wind Eng Ind Aerodyn 98(1):34-46

Jiang Z, Liu T, Gu H, Guo Z (2021) A numerical study of aerodynamic characteristics of a high-speed train with different rail models under crosswind. Proc Inst Mech Eng Part F J Rail Rapid Transit 235(7):840-853

Launder BE, Spalding DB (1972) Lectures in mathematical models of turbulence. Academic, London, pp 358-426

Liu T, Jiang Z, Chen X, Zhang J, Liang X (2019) Wave effects in a realistic tunnel induced by the passage of high-speed trains. Tunn Undergr Space Technol 86:224-235

Liu Z, Chen Y, Wu Y, Wang W, Li L (2017) Simulation of exchange flow between open water and floating vegetation using a modified RNG k- $\varepsilon$ turbulence model. Environ Fluid Mech 17(2):1-18

Lü M, Li Q, Ning Z, Ji Z (2018) Study on the aerodynamic load characteristic of noise reduction barrier on high-speed railway. J Wind Eng Ind Aerodyn 176:254-262

Markatos NC (1986) The mathematical modelling of turbulent flows. Appl Math Model 10:190-220 
Niu J, Wang Y, Zhang L, Yuan Y (2018) Numerical analysis of aerodynamic characteristics of high-speed train with different train nose lengths. Int J Heat Mass Transf 127:188-199

Olsen NRB (2000) CFD algorithms for hydraulic engineering. Norway: Department of Hydraulic and Environmental Engineering, The Norwegian University of Science and Technology

Piller M, Nobile E, Hanratty TJ (2002) DNS study of turbulent transport at low Prandtl numbers in a channel flow. J Fluid Mech 458:419-441

Rocchi D, Tomasini G, Schito P, Somaschini C (2018) Wind effects induced by high speed train pass-by in open air. J Wind Eng Ind Aerodyn 173:279-288

Rollet-Miet P, Laurence D, Ferziger J (1999) LES and RANS of turbulent flow in tube bundles. Int J Heat Fluid Flow 20(3):241-254

Schetz JA (2001) Aerodynamics of high-speed trains. Annu Rev Fluid Mech 33(1):371-414

Soper D, Baker C, Jackson A, Milne DR, Le PL, Watson G, Powrie W (2017) Full scale measurements of train underbody flows and track forces. J Wind Eng Ind Aerodyn 169:251-264

Willemsen E (1997) High Reynolds number wind tunnel experiments on trains. J Wind Eng Ind Aerodyn 69-71:437-447

Wissink JG (2003) DNS of separating, low Reynolds number flow in a turbine cascade with incoming wakes. Int J Heat Fluid Flow 24(4):626-635

Xiong X, Yang B, Wang K, Liu T, He Z, Zhu L (2020) Full-scale experiment of transient aerodynamic pressures acting on a bridge noise barrier induced by the passage of high-speed trains operating at $380-420 \mathrm{~km} / \mathrm{h}$. J Wind Eng Ind Aerodyn 204:1-9

Yan B, Chen Y, Dai GL (2014) Dynamic response of fly-over cable-stayed bridge and bridge deck track structure under aerodynamic force of high-speed train. China Rail Sci 35(5):24-29

Yang N, Zheng X, Zhang J, Law SS, Yang Q (2015) Experimental and numerical studies on aerodynamic loads on an overhead bridge due to passage of high-speed train. J Wind Eng Ind Aerodyn 140:19-33

Zheng J, Li Q, Li X, Luo Y (2020) Train-induced fluctuating pressure and resultant dynamic response of semienclosed sound barriers. Shock Vib 2020:6901564

\section{Publisher's Note}

Springer Nature remains neutral with regard to jurisdictional claims in published maps and institutional affiliations.

\section{Submit your manuscript to a SpringerOpen ${ }^{\odot}$ journal and benefit from:}

- Convenient online submission

- Rigorous peer review

- Open access: articles freely available online

- High visibility within the field

Retaining the copyright to your article

Submit your next manuscript at $\gg$ springeropen.com 